\title{
Book Review: E-Learning and the Science of Instruction
}

\author{
Murat Ataizi \& Aras Bozkurt \\ Anadolu University, Turkey \\ "It's not the delivery medium, but rather the instructional methods that cause learning" \\ Clark and Mayer
}

\section{Introduction}

This book is authored by Ruth C. Clark and Richard E. Mayer. The 3rd edition of the book was published in 2011 by Pfeiffer, San Francisco, USA. The book has a total of 507+xviii pages. The ISBN of the book is $978-0470874301$.

As far as the authors of E-Learning and the Science of Instruction are concerned, Ruth C. Clark is a specialist in instructional design and technical training; Richard E. Mayer is a professor of psychology at the University of California and educational psychologist who is widely known for multimedia learning theory.

E-learning is the rising star of 21st century education. In today's world, individuals are living in the age of digital transformation and the globe is experiencing the e-learning revolution. The notion of e-learning premises us effective, efficient, and appealing learning opportunities (synchronous or asynchronous) through the computer and network technologies. Currently, though e-learning is accepted and regarded as mainstream by many, and has been put into practice already, the idea is still in its infancy and advancing rapidly both in theory and practice. Therefore, there is a growing need for references that meet this need and resources that deal with e-learning from different aspects.

\section{Chapters}

Carefully revised and updated, the third edition of E-Learning and the Science of Instruction: Proven Guidelines for Consumers and Designers of Multimedia Learning, has 17 chapters that provide evidence-based guidelines for different e-learning forms, and offers a comprehensive review of multimedia learning for both users and designers. The book contains multimedia design principles with current research, and offers effective e-learning guidelines for designers, developers, and consumers of e-learning with a clear, concise language that anyone can easily comprehend.

E-Learning and the Science of Instruction is a well-designed and carefully-structured book. It has a modular nature. E-learners can read the whole book to gain a holistic perspective or merely can read any relevant chapter they need. Each chapter has a brief introduction that outlines the chapter and explains what is new in this third edition. Each chapter is also outlined with a basic structure. At the beginning of chapters 2-16, there are sections titled as "design 
dilemma" which have a scenario-based narration and intend to think about a problem related to relevant chapter and as a follow up section at the end, there are "design dilemma: resolved" sections which provide answers and justification. At the end of each chapter, key points are summarized with a helpful checklist which is easy to digest and "coming next" part is given as a warm up section for the following chapter. Suggested readings for the ones who want to go further and want to dig deep are also given in the final part of each chapter. It seems that Clark and Mayer also applied some principles they mentioned in their book.

In general, Chapters 1-3 are defining, describing, and summarizing e-learning; Chapters 4-10 summarize the multimedia principles; Chapters 11-15 focus on guidelines related to important instructional methods and approaches in e-learning; Chapter 16 presents games and simulations in e-learning, and finally Chapter 17 summarizes previous chapters with e-learning examples.

Chapter 1 is titled as "E-Learning Promise and Pitfalls". In this chapter e-learning is defined as "instruction delivered on a digital device such as a computer or mobile device that is intended to support learning"; in addition, potentials and drawbacks of e-learning were identified.

Chapter 2 explains "How Do People Learn from E-Courses?" This chapter discusses how learning works and how to help people learn. After giving rationale, learning with multimedia is explained from educational psychology and e-learning perspectives in this chapter.

Chapter 3 is about "Evidence-Based Practice". This section addresses the importance of using instructional methods that have been shown to be effective based on high-quality research. It is also highlighted that the main idea of this book is evidence-based practice: the idea that instructional techniques should be based on research findings and research-based theory.

Chapter 4 deals with "Applying the Multimedia Principle". In this part of the book, it is explained that it is more effective to use words (written or spoken) and graphics (static illustrations such as drawings, charts, graphs, maps, or photos; and dynamic graphics such as animation or video) together rather than to use words only. Authors indicate that using multimedia presentations will encourage learners to engage in active learning by mentally representing the material in words and in pictures and by mentally making connections between the pictorial and verbal representations. It is also explained that people learn better when graphic organizers are added to text.

Chapter 5 focuses on "Applying the Contiguity Principle". According to this principle, it is better to integrate text and graphics (that is, placing printed words next to the part of the graphic they describe or present spoken words at the same time as a corresponding graphic) as it reduces use of cognitive resources rather than separating them.

Chapter 6 examines "Applying the Modality Principle". In this chapter, it is stated that using words in brief and clear audio narrations rather than on-screen text can result in significant learning gains.

Chapter 7 describes "Applying the Redundancy Principle". This principle suggests explaining visuals with words in audio or text, but not both at the same time. It is also indicated that individuals learn better from concurrent graphics and audio than from concurrent graphics, audio, and on-screen text. It is advocated that psychological advantage of presenting words in audio alone is that you avoid overloading the visual channel of working memory. 
Chapter 8 discusses "Applying the Coherence Principle". According to this principle, adding any material that does not support the instructional goal doesn't help. It is explained that adding interesting (entertaining or motivational elements such as dramatic stories, pictures, or background music) but unnecessary material to e-learning can harm the learning process.

Chapter 9 presents "Applying the Personalization Principle". This chapter supports the view that using a conversational style of writing (including using first and second person language) and a friendly human voice. It is also underlined that using virtual coaches, on-screen pedagogical characters which help to guide the learning processes during an instructional episode and induce the learner to engage with the computer as a social conversational partner, is effective.

Chapter 10 emphasizes "Applying the Segmenting and Pretraining Principles". This principle is about managing complexity by breaking a lesson into parts. This chapter focuses on techniques for managing essential processing, including segmenting (breaking a lesson into manageable segments) and pretraining (providing pretraining about the names and characteristics of key concepts).

Chapter 11 deals with "Leveraging Examples in E-Learning". In this chapter, application of multimedia principles to modeling/worked examples, which are used for tasks that involve problem solving and multiple appropriate solutions, were explained.

Chapter 12 answers a question: "Does Practice Make Perfect?" It is stated in this chapter that better learning usually occurs with interactions in e-learning. So, it is a necessity to distribute interactions throughout the instructional environment and apply Mayer's multimedia principles to the design and layout of e-learning interactions. On the other hand, it is also highlighted in this chapter that while practice does not necessarily lead to perfect, deliberate practice that includes effective feedback does.

Chapter 13 explains "Learning Together Virtually". This chapter presents guidelines regarding the optimal use of computer mediated collaborative learning and summarizes common social software and some of their applications to e-learning.

Chapter 14 is titled as "Who's in Control?" This chapter is about navigational features. The terms learner control (e-learning systems offering more choices) and program control (systems with fewer options) are explained in this part of the book.

Chapter 15 focuses on "E-Learning to Build Thinking Skills." This section provides evidence and guidelines for using e-learning to build job-specific thinking or problem-solving skills. In this edition of the book, the authors expanded their discussion of domain-specific whole-task multimedia learning environments and offered more details on cognitive task analysis to identify job-specific thinking processes.

Chapter 16 examines "Simulations and Games in E-Learning." In this part of the book, it is stated that there haven't been enough findings about principles to guide design of effective learning games. On the other hand, the authors took an evidence-based approach to help elearners define tradeoffs and leverage proven techniques when considering simulations and games to achieve their learning goals and to maximize the learning potential of games and simulations. 
Chapter 17 explains "Applying the Guidelines." In this final chapter, all the guidelines they have discussed consolidated by describing how they should be applied or how they are violated in three sample e-learning lessons.

\section{Conclusion}

In conclusion, this book offers evidence based on proven guidelines for computer mediated elearning practices and stands as a "must have book" for e-learners. What makes this book valuable is its approach to explain design principles. Authors of this book not only explain elearning design basics, but also support their views by empirical evidences integrated into context. This book doesn't merely narrate as it is expected, but demonstrates what works in reality. All in all, computer based technology and pedagogy; theory and practice are blended in a melting pot providing step by step clear examples for e-learners for the readers.

Technology has been advancing beyond belief since the third edition of this book and previously. Emerging technologies such as tablets and smart phones became extremely popular and widely available. Through these emerging technologies not only clicking, but also touching, shaking and gesturing became a way of interaction. In addition, screen layout and navigation options adapted themselves in parallel with recent developments. On that account, in the next edition of this book, multimedia principles might be updated according to new information and communication technologies, tools and interaction ways.

After all, E-Learning and the Science of Instruction presents a comprehensive guide and solid evidences for designers, developers, or consumers of e-learning and helps e-learners to design, develop, and evaluate e-learning.

Correspondence: Murat Ataizi, Associate Professor, Faculty of Communication Sciences, Anadolu University, Yunus Emre Campus, Eskisehir, Turkey 